\title{
Influence of Controlled Permeability Formwork on the Permeability of Concrete
}

\author{
W. Lin, Q. Jiang, and J. Liu \\ State Key Laboratory of High Performance Civil Engineering Materials, \\ Jiangsu Research Institute of Building Science \\ J. Liu \\ School of Materials Science and Engineering, Southeast University
}

\begin{abstract}
Corrosion of steel reinforcement related to the intrusion of chloride ion is still the main threats to the durability of concrete structure, especially in marine environment. For the purpose of delaying the $\mathrm{Cl}^{-}$concentration at the surface of steel reinforcement reaching the critical value leading to initial corrosion, the permeability of concrete is usually improved by optimizing the concrete mixture to achieve high compatibility as well as optimized pore structure. In recent years, controlled permeability formwork (CPF) which was originally developed to obtain much smoother surface of the concrete proves to promote the service performance of the concrete by enhancing the surface layer which could protect the structure from $\mathrm{Cl}^{-}$further. In this paper, influence of the CPF on the permeability of concrete was studied with different water to binder ratio, fluidity, and fly ash content. Furthermore, mathematical models were established to discuss the influence on the permeability of the concrete and service life of the structure.
\end{abstract}

\section{INTRODUCTION}

Corrosion of steel reinforcement related to the intrusion of chloride ion is still the main threats to the durability of concrete structure, especially in marine environment (Mehta \& Monteiro, 2006). For the purpose of delaying the $\mathrm{Cl}^{-}$concentration at the surface of steel reinforcement reaching the critical value leading to initial corrosion, the permeability of concrete is usually improved by optimizing the concrete mixture to achieve high compatibility as well as optimized pore structure. In recent years, controlled permeability formwork (CPF) which was originally developed to obtain much smoother surface of the concrete proves to promote the service performance of the concrete by enhancing the surface layer which could protect the structure from $\mathrm{Cl}^{-}$further (Dai, Akira, Wittmann, Yokota, \& Zhang, 2010; Ibrahim, Al-Gahtani, Maslehuddin, \& Almusallam, 1997; Suryavanshi \& Swamy, 1997).

Unlike the conventional impermeable formwork, CPF can remove the air bubbles and excess water migrating to the surface during the pouring and vibrating of concrete mixtures (Schubel, Warrior, Elliott, \& Jones, 2008). Thus, a denser and stronger surface layer could be fabricated to achieve better performance. It is reported that, the concrete surface generated in contact with the CPF was highly impermeable with a water-cement $(\mathrm{w} / \mathrm{c})$ ratio as low as 0.3 , for a concrete mixed at a w/c ratio of $0.50-0.55$. And the sorptivity, chloride and oxygen diffusivity, carbonation penetration and freeze-thaw resistance (Coutinho, 2001; McCarthy, Giannakou, \& Jones, 2001; Nolan, Basheer, \& Long, 1995) can be improved obviously.

In this article, influence of the CPF on the permeability of concrete was studied with different $\mathrm{w} / \mathrm{b}$ ratio, fluidity, and fly ash content. Furthermore, mathematical models were established to discuss the influence on the permeability of the concrete and service life of the structure.

\section{EXPERIMENTAL}

\subsection{Materials}

P II Portland cement (according to GB175-2007), Grade I fly ash (according to GB/T1596-2005), basalt aggregate ranged in 5-20 mm and sand with a fineness modulus of 2.7 were used to cast the tested concrete blocks. The chemical component of the mentioned cementitious materials is shown in Table 1. The Burnett CPF used in this research has an average pore diameter of $40 \mu \mathrm{m}$. Polycarboxylate superplasticizer (SP) by Jiangsu Sobute New Materials Co., Ltd. was added to achieve a pleasing slump.

Table 1. Chemical composition of the cementitious materials (wt\%).

\begin{tabular}{lccccccl}
\hline & $\mathrm{SiO}_{2}$ & $\mathrm{Al}_{2} \mathrm{O}_{3}$ & $\mathrm{Fe}_{2} \mathrm{O}_{3}$ & $\mathrm{CaO}$ & $\mathbf{M g O}$ & $\mathrm{SO}_{3}$ & $\mathrm{LOI}$ \\
\hline Cement & 18.9 & 4.46 & 3.21 & 62.94 & 3.75 & 3.98 & 3.76 \\
Fly ash & 50.6 & 33.6 & 6.51 & 6.28 & 1.09 & 0.62 & 1.1 \\
\hline
\end{tabular}




\subsection{Specimen preparation}

Two blocks were prepared with the size of $500 \mathrm{~mm} \times 500 \mathrm{~mm} \times 200 \mathrm{~mm}$ for each mixture proportion. One of them was cast into a steel mould with CPF liner (its Water was poured into the box until $5 \mathrm{~mm}$ higher than the top surfaces. Core samples were removed out from the water in certain intervals, wiped the outside and weighed as $w_{1}$. The water adsorption of each sample, $W$, was calculated as: code name, CPF), compared with the other one without CPF(its code name, No CPF).

To ensure the firm and smooth attachment of the CPF to the mould inner surface, the following steps were carried out.

1. Spray the specific adhesive to each inner surface of the mould, about $200 \mathrm{~g} / \mathrm{m}^{2}$.

2. Unfold the CPF liner on the mould surfaces, stick it from center to the surrounds gradually. In each side of the mould, a $5 \mathrm{~mm}$-wide gap without CPF liner is reserved to be a passage of excess water and air. The mix proportions in this study are shown in Table 2.

Table 2. Concrete mixture proportions $\left(\mathrm{kg} / \mathrm{m}^{3}\right)$

\begin{tabular}{ccrcccc}
\hline No. & Cement & FA & Sand & Gravel & Water & SP \\
\hline 1 & 450 & 0 & 780 & 1077 & 145 & 3.8 \\
2 & 315 & 135 & 780 & 1077 & 145 & 3.5 \\
3 & 400 & 0 & 780 & 1077 & 182 & 3.6 \\
4 & 280 & 120 & 780 & 1077 & 182 & 3.3 \\
\hline
\end{tabular}

The prepared mixtures were cast into the abovementioned molds and compacted using an internal vibrator. Much attention was paid to ensure that the vibrator had not contacted with the formwork liner. After $24 \mathrm{~h}$ curing, the formwork was removed and the blocks were cured at $20 \pm 2{ }^{\circ} \mathrm{C}$ and over $95 \%$ relative humidity.

The surface morphology was captured using a digital camera.

The strength of the samples was tested by rebound method at the curing age of 28 days. Data was analyzed according to JGJ/T 23-2001.

Afterwards, cylinders with diameter of $100 \mathrm{~mm}$ were cored deep to $50 \mathrm{~mm}$ from the surfaces of $500 \mathrm{~mm} \times 500 \mathrm{~mm}$. The cylinder sample had a pristine surface from the large block (top surface) and all the other surfaces, including profile and underside were generated freshly during cored. The water sorption test and chloride ion diffusion coefficient test (Coulomb electric flux method) were based on these cylinders.

In the water adsorption test, the profiles and undersides of the cored cylinders were covered with epoxy, only the top surface remained its original appearance. Triple samples were prepared for each block. They were dried in oven at $60^{\circ} \mathrm{C}$ for $48 \mathrm{~h}$, then weighed as $w_{0}$. The samples were then put into a plastic box, with their top surfaces facing down.

$$
W=\left(w_{1}-w_{0}\right) /(\pi \times 0.05)
$$

The adsorption coefficient was the slope of water adsorption - square root of immersion time.

Coulomb electric flux method was carried out based on GB/T 50082-2009.

\section{RESULTS AND DISCUSSION}

\subsection{Visible surface morphology}

Visible surface morphology of concrete blocks cast with conventional steel mold and CPF liner are shown in Figure 1. Obviously, there were many irregular blowholes on the surface of concrete block with steel mold. This was because that air bubbles in the concrete mixture migrating outside and breaking while meeting the steel mold surface. However, the concrete block casted with CPF liner had a smooth surface without any visible defects. The surface of concrete block without CPF liner was gray and many wavy lines existed. This might be caused by too much bleeding water gathering on the block surface. CPF block had a much darker and more homogeneous surface. From the picture, many small swellings spread around the surface, which might be the accumulation of cementitious particles. Basically, darker surface was thought to be an indication of more cement or its hydration products. According to this, the obstruction effect of CPF on cement particles could be verified.

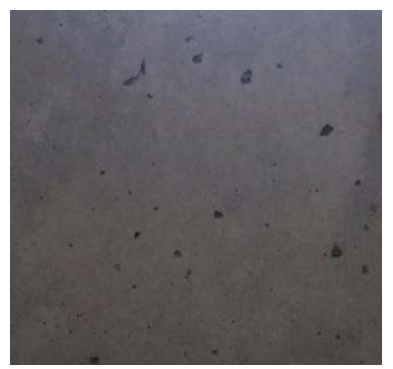

(a)

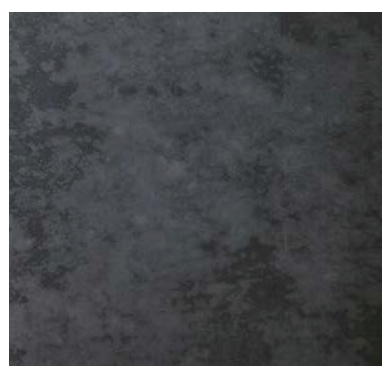

(b)
Figure 1. Visible surface morphology of concrete blocks. (a) No CPF liner. (b) With CPF liner.

\subsection{Strength}

Strength result of the concrete blocks by rebound method is shown in Figure 2. It is well known that the strength of concrete decreases with the increasing of $w / b$ ratio. And for the fly ash content, its pozzolanic effect could seldom be exhibited with 28 days normal curing. However, for each mixture proportion, the specimen with CPF has higher rebound strength than 
the one without CPF. This was due to the removal of water and air bubbles at the surface layer of concrete through the pores of CPF. The increasing percentage was $3.9,9.1,5.1$, and $11.9 \%$, respectively, for \#1, \#2, $\# 3$, and \#4. It seems that high w/b ratio and fly ash content are better for the function of CPF. It might be due to more excessive water could be removed by CPF.

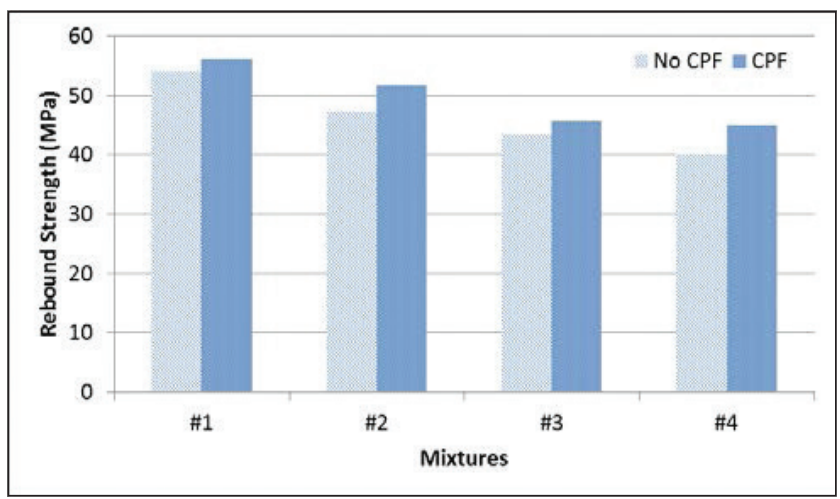

Figure 2. Effect of CPF on the rebound strength of concrete.

\subsection{Water sorption}

Figure 3 shows the effect of CPF on the water adsorption coefficient calculated with the data within 100 min. Water adsorption coefficient is one of the index for the permeability of concrete, especially for the surface layer. Figure 3 indicates that, with the increasing of $\mathrm{w} / \mathrm{b}$ ratio and fly ash content, the water adsorption coefficient increased due to the change of pore structure. And also, for each mixture proportion, the water adsorption coefficient of the specimens with CPF is much lower than the one without CPF. CPF could optimized the pore structure of the surface layer by removing excessive water and air bubble to decrease the rate of water sorption of hardened concrete resulted in low permeability. Like the tread analyzed in Section 3.2, high $\mathrm{w} / \mathrm{b}$ ratio and fly ash content are better for the function of CPF to obtain lower extent of permeability.

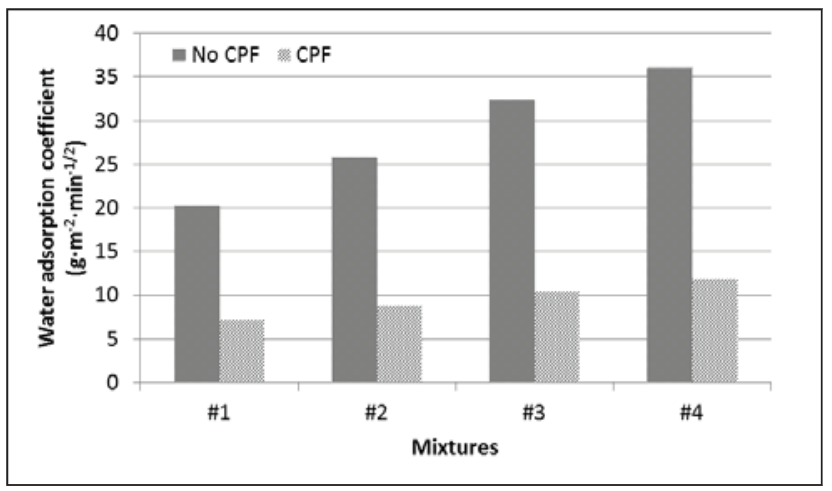

Figure 3. Effect of CPF on the water adsorption coefficient.

\subsection{Resistance to chloride ion penetration}

Coulomb electric flux test of concrete specimens with or without CPF were tested after electrifying for $6 \mathrm{~h}$ by $60 \mathrm{~V} \mathrm{DC}$ voltage. The result could be seen in Figure 4. It is considered that the value of Coulomb electric flux indicates the permeable of the whole specimen including surface and inner. With the effect of CPF liner, the value of Coulomb electric flux dropped 19.1, 20.0, 32.4, and $31.1 \%$, respectively, for mixture \#1, \#2, \#3, and \#4. As the electric field applied, the inner permeability of the concrete specimen was taken into account to the value. However, CPF made a great contribution to improving the permeability of the specimen as a whole.

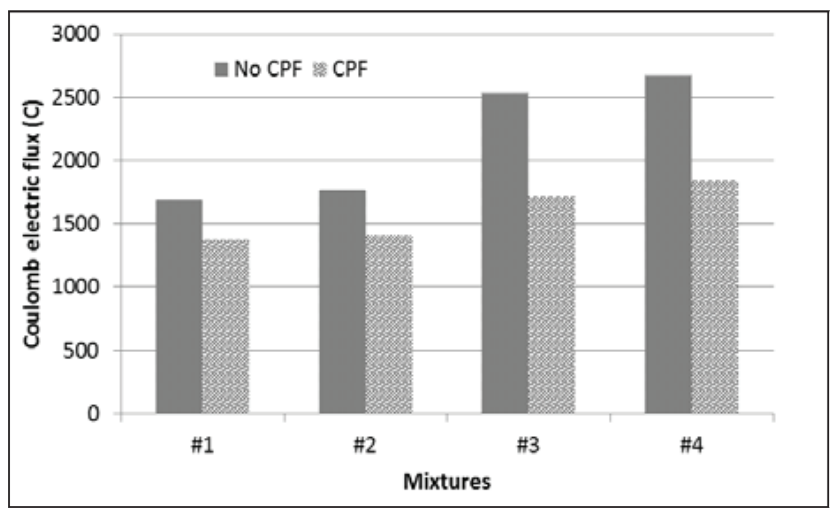

Figure 4. Effect of CPF on the chloride ion penetration resistance.

\subsection{Finite element method (FEM) analysis}

AFEM model was built with PDETool included in Matlab software to analysis the influence of the decrease of permeability in concrete surface layer by CPF on the durability of the concrete structure.

The 2-D geometry was set up as Figure 5. R2 represents the surface layer of concrete with a width of 1 . And R1 represents the inner concrete with a width of 30 and a permeability of 0.946 . Rebar was put at a distance of 5 from concrete surface. The permeability of R2 was set to $0.946,0.473$, and 1.419 , respectively, to simulate the normal (0), good (+), and poor (-) surface layer of concrete.

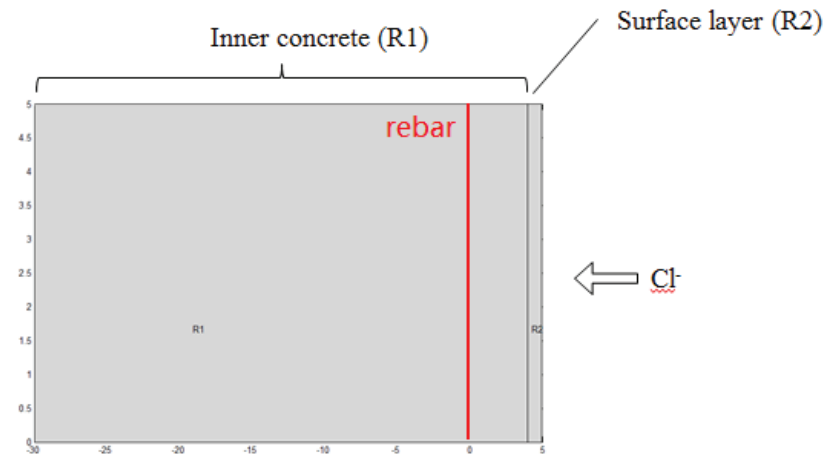

Figure 5. Geometry setup of the FEM analysis. 
The result of the simulation of the time of 50 was shown in Figure 6. And the colors indicate the concentration of $\mathrm{Cl}^{-}$distribution within the concrete. The concentration of $\mathrm{Cl}^{-}$at the position of rebar with time changing was collected and plotted in Figure 7. Figure 7 shows that with the improvement of surface layer, the concentration distribution of $\mathrm{Cl}^{-}$was significantly changed from the normal surface and poor surface. The surface layer plays an important role in resistance of the intrusion of $\mathrm{Cl}^{-}$into the inner concrete. Given 0.3 as the critical concentration value of $\mathrm{Cl}^{-}$, the service life of concrete structure with poor surface, normal surface, and good surface was 19,21 , and 30 , respectively. That means the service life of the concrete structure could be increased to $42.9-57.9 \%$ with good surface.

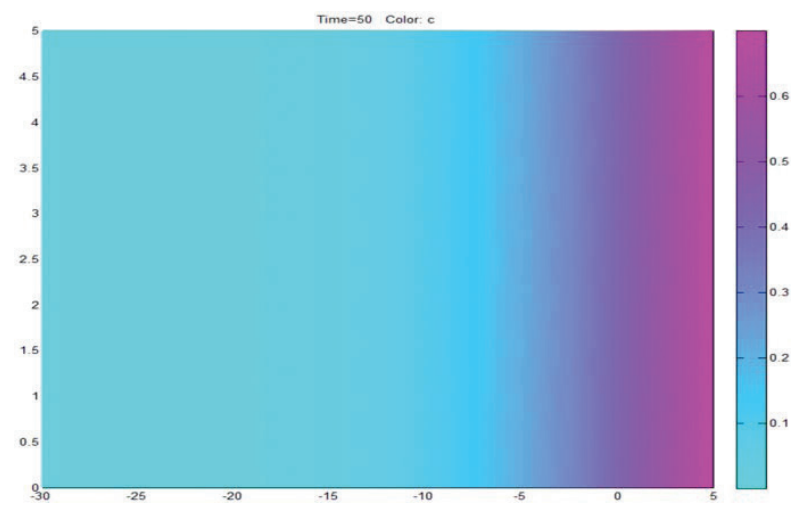

Figure 6. Simulation result of the FEM.

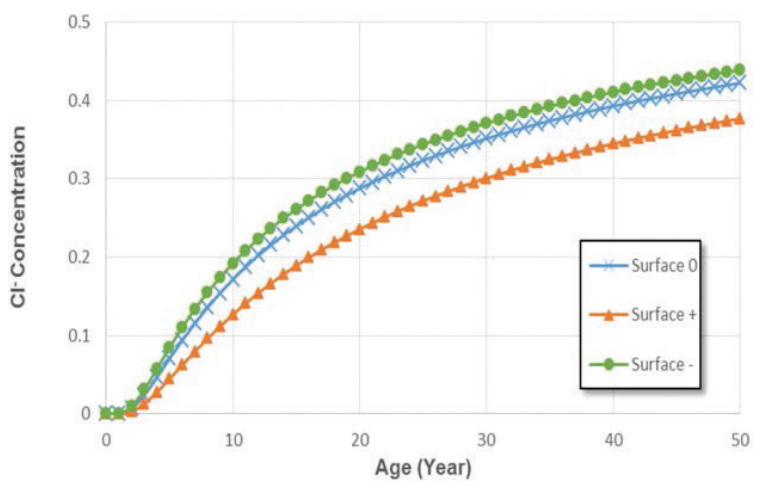

Figure 7. The $\mathrm{Cl}^{-}$concentration at rebar position.

\section{CONCLUSIONS}

Results obtained throughout the laboratory tests and simulation work led to the following conclusions: CPF could make the concrete surface blow-hole free with no blemishes, which prepares the ground for better permeability performance of concrete.

By removing excessive water and air bubbles, CPF could make better the concrete performance such as rebound strength, especially permeability, proved by water sorption test and Coulomb electric flux test. CPF has better performance on the concrete mixture with high $w / b$ ratio and proper fly ash content.

FEM analysis shows that concrete structure with strengthened surface layer by CPF could significant increase the service life of the structure.

\section{ACKNOWLEDGMENTS}

This study was financially supported by National Natural Science Foundation of China (Grant No. 51208235) and Natural Science Foundation of Jiangsu Province (Grant No. BK2012480).

\section{REFERENCES}

Coutinho, J. S. (2001). Effect of controlled permeability formwork (CPF) on white concrete. ACI Materials Journal, 98(2), 148-158.

Dai, J. G., Akira, Y., Wittmann, F. H., Yokota, H., \& Zhang, P. (2010). Water repellent surface impregnation for extension of service life of reinforced concrete structures in marine environments: The role of cracks. Cement and Concrete Composites, 32(2), 101-109.

Ibrahim, M., Al-Gahtani, A. S., Maslehuddin, M., \& Almusallam, A. A. (1997). Effectiveness of concrete surface treatment materials in reducing chlorideinduced reinforcement corrosion. Construction and Building Materials, 11(7), 443-451.

McCarthy, M. J., Giannakou, A., \& Jones, M. R. (2001). Specifying concrete for chloride environments using controlled permeability formwork. Materials and Structures, 34(9), 566-576.

Mehta, P. K., \& Monteiro, P. J. (2006). Concrete: Microstructure, properties, and materials (Vol. 3). New York, NY: McGraw-Hill.

Nolan, E., Basheer, P. A. M., \& Long, A. E. (1995). Effects of three durability enhancing products on some physical properties of near surface concrete. Construction and Building Materials, 9(5), 267-272.

Schubel, P. J., Warrior, N. A., Elliott, K. S., \& Jones, M. (2008). An investigation into the critical factors affecting the performance of composite controlled permeable formwork liners: Part I - Drainage medium. Construction and Building Materials, 22(7), 1551-1559.

Suryavanshi, A. K., \& Swamy, R. N. (1997). An evaluation of controlled permeability formwork for long-term durability of structural concrete elements. Cement and Concrete Research, 27(7), 1047-1060. 